\title{
THE ROLE OF 3D DOCUMENTATION FOR RESTORATION INTERVENTIONS. THE CASE STUDY OF VALFLORES IN LOURES, PORTUGAL.
}

\author{
L. Mateus ${ }^{1, *}$, V. Ferreira ${ }^{1}$, J. Aguiar ${ }^{1}$, P. Pacheco ${ }^{2}$, J. Ferreira $^{3}$, C. Mendes ${ }^{4}$, A. Silva ${ }^{5}$ \\ ${ }^{1}$ University of Lisbon, Lisbon School of Architecture, CIAUD, Lisbon, Portugal - (lmmateus, jaguiar, victor)@ fa.ulisboa.pt \\ ${ }^{2}$ Pedro Pacheco Arquitectos, Lisbon, Portugal - ppacheco@ppacheco.net \\ ${ }^{3}$ MATRIZVISTA, Lisbon, Portugal - joaonunesferreira.mv@gmail.com \\ ${ }^{4}$ ADPAC, Loures, Portugal - mendes.cristinaporfirio@gmail.com \\ ${ }^{5}$ Municipality of Loures, Divisão de Cultura | Unidade de Património e Museologia - ana_silva@cm-loures.pt
}

\section{Commission II - WG II/8}

KEY WORDS: Restoration, Partnership, Renaissance, Laser scanning, Photogrammetry, 3D Documentation

\begin{abstract}
:
The house and farm of Valflores, located near Lisbon, are an important evidence of the Portuguese Renaissance civil architecture from the first half of 16th century, built by Jorge de Barros, the overseer of the Portuguese king, D. João III, in Flanders. Its style has its roots in Italian villas. As was common at that time, the property was a villeggiatura site. In 1982 the house and the farm were listed as property of public interest. In 2000 the property was inserted in a Portuguese list of heritage at risk and in 2001 the property was in a state of pre-ruin. It was bought by the municipality in 2006. After 2007 a partnership between a Local Heritage Association (ADPAC), the Municipality of Loures and the Lisbon School of Architecture developed a series of initiatives for the safeguard and restoration of this Heritage. Several studies were performed, including multiple three-dimensional surveys on several occasions. Ultimately, these studies led to the development of a restoration project in 2016 for European funds application. At the present date, the restoration works are going on. The objective of this paper is the discussion of how three-dimensional documentation played a fundamental role on the several stages of this process, namely after 2007, permitting to gain insights about metrics, space and form distributions, deformations, structural condition, state of conservation, history, and allowing dissemination and public engagement.
\end{abstract}

\section{INTRODUCTION}

Heritage restoration and rehabilitation are multidisciplinary activities that require inputs from diverse fields of knowledge such as architecture, engineering, archaeology, surveying, among others. At the same time, it is desirable the engagement between all the stakeholders, including municipalities, public agencies, the scientific community, the professionals of the field, local associations, and the public in general (Cramer et al, 2007). Visual data play an important role in all of this. Nowadays, terrestrial laser scanning and digital photogrammetry are essential tools to produce such data. For the professionals of conservation, data generated with these methods is used to produce plans, sections, and elevations of the existing buildings, 3D modelling, pathology assessment, structural integrity verification, stratigraphic analysis, and for communication purposes. Not substituting direct contact with the built fabric, these methods allow virtual visits to the sites to clarify multiple issues. Thus, they minimize the need to visit them physically (Hoon, 2019; Remondino et al, 2010; Mateus et al, 2019a; Mateus et al, 2019b). Heritage professionals are not the only ones to benefit. Through web platforms, social networks, or video games, the public can also access this type of information. In this way, the public can engage with heritage, raise awareness to heritage values and contribute to heritage preservation (Fernández et al, 2019).

\section{THE HOUSE AND FARM OF VALFLORES}

Valflores, in Loures near Lisbon, is the name by which it is known one of the most important testimonies of Portuguese Renaissance civil architecture of the first half of the 16th century.
One of Valflores' values lies in the fact that, despite some degradation, it has reached our days with few changes. Its style is rooted in Italian villas and it integrates a very interesting hydraulic system for water supply. The original owner, Jorge de Barros, was the overseer of the Portuguese king, D. João III, in Flanders, and built Valflores as a villegiatura house, near the capital, as it was common among noble families (Pires, 2013). It is implanted in the middle of a hill modelled with terraces. Each terrace corresponded to a different agricultural production. The upper part was occupied by rainfed crops, namely olive trees. The lower parts, where water was abundant, corresponded to the gardens, fruit farm, and leisure areas. The water came from a stream, a mine and two wells. It was captured, distributed by two aqueducts, and then stored in a few tanks. From this, it is evident that this asset should be regarded as a complex system rather than just a house. In the aerial images of figure 1, the top one dated from 1944 and the lower one from 2007, this hydraulic structure is clearly visible, and it corresponds to one of the key values of this heritage that must be preserved. During this period of sixty years some transformations occurred due to construction of infrastructures and housing.

Until the second half of 19th century the property was used as an agricultural farm and housing. On this date, it was lost by the Barros family, to creditors. It the late 19th century the property was bought by the Reynolds family. The records of that time indicate that the property was in good state of conservation. This family never used the property as housing. Instead they rented it. Then it started to be used just as an agricultural warehouse. After the sixties of the 20th century, the

\footnotetext{
* Corresponding author
} 
compartments on the lower floor of the house begun to be used as a pigsty, stable, chicken coop, byre, among other uses. This type of use introduced some degradation. However, the worst happened after the property was abandoned in the late nineties of the 20th century (Noé et al, 2001).

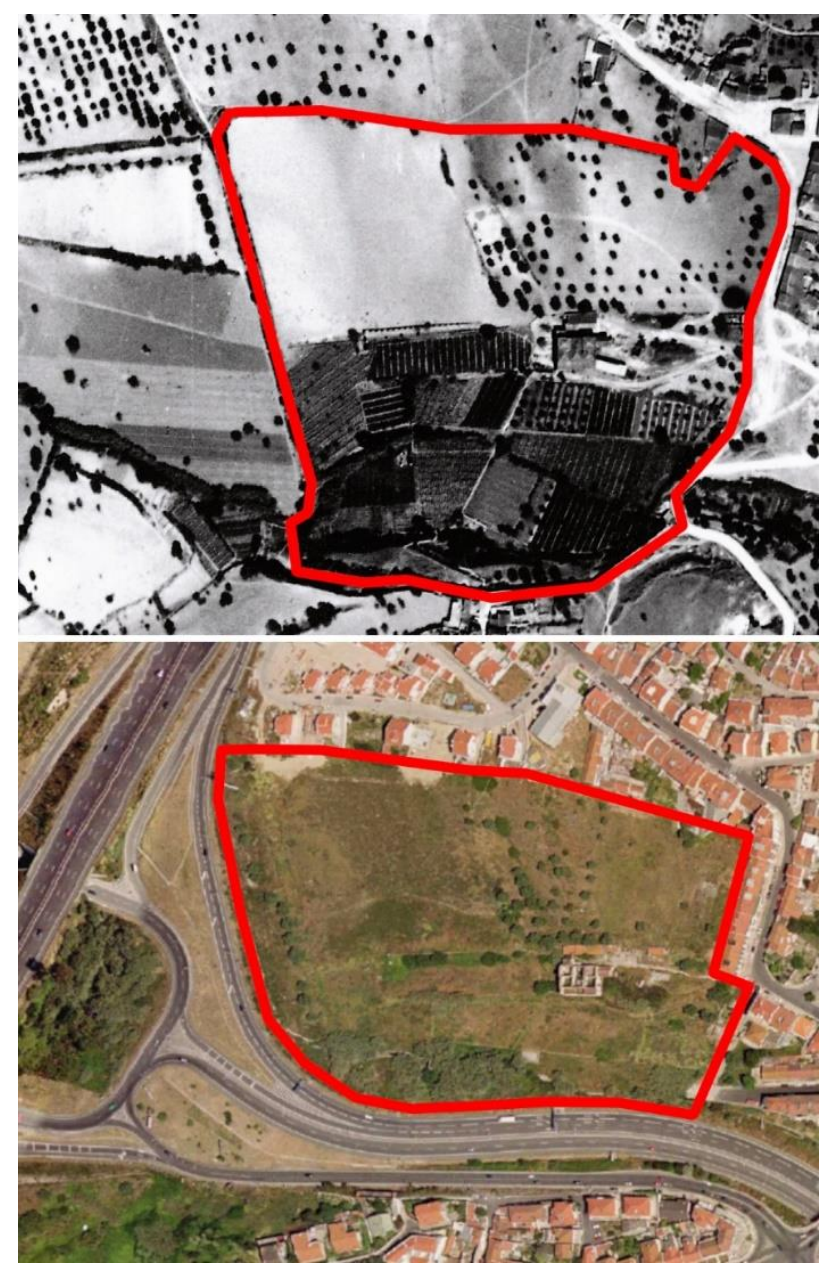

Figure 1. Aerial images oriented North/South. Top: 1944

(Source: Instituto Geográfico e Cadastral), Bottom: 2007 (Source: Municipality of Loures).

The lack of maintenance led to the loss of roofs and loggia. And this, in turn, resulted in several structural problems in walls, vaults, mortars, finishes, among others.

In figure 2 we can see the progress of degradation of the house between 1960 and 2001.

In 1982 the house and the farm were listed as property of public interest. In 2000 the property was included in a Portuguese list of heritage at risk. That led the former General Directorate of National Buildings and Monuments (DGEMN) to conduct a survey of the house where the principal anomalies were recorded through rectified imagery. This survey was incomplete because, for alleged security reasons, the lower floor compartments were not visited. It was concluded that the house was at risk of collapse. In 2001, after the fall of the loggia, the property was in a state of pre-ruin. Finally, it was acquired by the municipality of Loures from the Reynolds family in 2006.
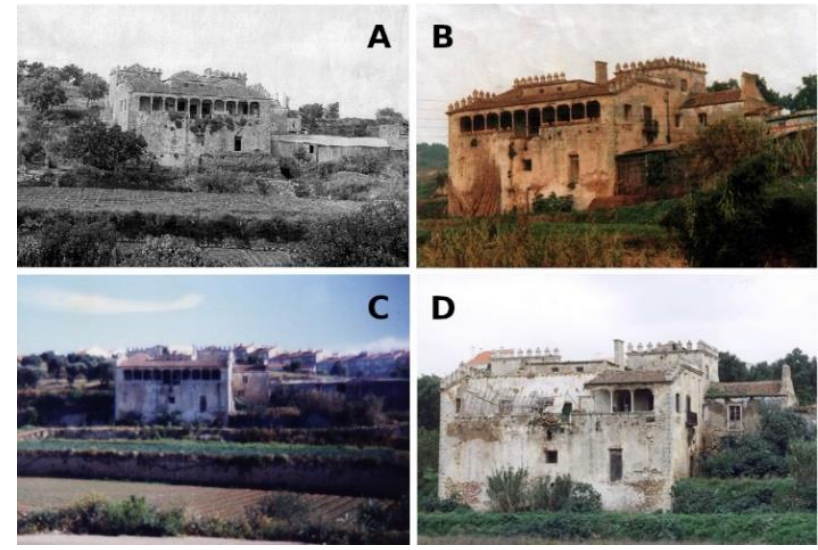

C

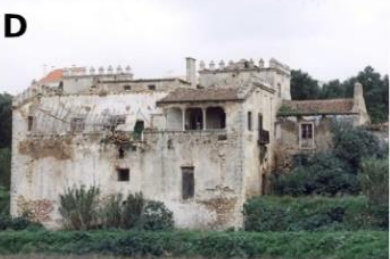

Figure 2. A: 1960, B:1991, C: 1994(8), D: 2001. Source: SIPA and ADPAC.

In 2007, after a long period of uncertainty about the future of this heritage, a partnership was established between the Local Heritage Association (ADPAC), the Municipality of Loures and the Lisbon School of Architecture. This allowed to develop a series of initiatives for the safeguard and restoration of Valflores. Several studies have been developed, including updates to existing documentation and the production of new data through multiple three-dimensional surveys at various occasions, including during restoration and conservation work. Ultimately, these studies led to the elaboration of a conservation and restoration project in 2016. The objective of this project was the submission of an application to obtain European funds to carry out the interventions. The project foresees that the conservation and restoration works take place in three phases. The works of structural consolidation were concentrated in the first phase. This includes the house and the main aqueduct. In the second phase, roofs will be restored and the water drainage in the exterior will be solved. In the third phase it will be done a thorough restoration process of each compartment of the house. At the present date, the restoration works corresponding to phase one are finished. While the works of these three phases are being carried out, there is a time gap to reflect on the future use of this heritage. A key to the reflection on this future use is the definition of a set of principles that positively restrict the options that will be possible to adopt. The ultimate consequence of this process will be the development of an architectural project that will establish the future uses of Valflores. For this purpose, it is interesting to notice the role of Lisbon School of Architecture. During two semesters, between 2016 and 2018, and using data produced during all this process, the students of the course of Conservation, Restoration and Rehabilitation were asked to develop proposals for the future of Valflores. Those were exhibited and presented to the municipality, enhancing and enriching the discussion about the future of the territory in which Valflores is inserted.

Thus, the objective of this paper is the discussion of how the three-dimensional documentation played a fundamental role on the several phases of this process, namely after 2007, permitting to gain insights about metrics, space and form distributions, deformations, structural condition, state of conservation, history, and allowing dissemination and public engagement. We will also discuss how three-dimensional documentation was used in the restoration project and outside that context, how it served the purposes of the intervention and how the multiple agents involved used it. 


\section{THE DOCUMENTATION PROCESS AND THE RESTORATION PROCESS}

In any intervention in existing fabric it is mandatory to gather all the available information about the subject, to judge it and to decide if and what extra information is needed. This information is twofold. On the one hand it is written (historical, past interventions reports, etc.) and on the other hand it is graphical (photographs, pictures, previous surveys, etc). For this paper we are mostly concerned with graphical information and specifically the one that can be obtained with photogrammetry and laser scanning.

\subsection{Existing graphical documentation and preliminary visits to the site}

The first graphical elements gathered were archive photographs and the 2000 survey conducted by DGEMN. Our first approach in 2007 , still with traditional methods, was to complete and update, as far as possible, those elements, and to complement them with photographs. For example, figure 3 shows how existing plans were used as a support to take annotations and measurements about the actual condition that were, later, integrated in accurate drawings.



Figure 3. Using existing plans from DGEMN as support for annotations.

This action, still without the above-mentioned tools, resulted in a preliminary report where some preventive and corrective actions were prescribed: i) the installation of a provisional roof, ii) structural consolidation of walls, iii) restoration of the vaults and of other structural elements. This report was delivered to the municipality in the end of 2008. One of the actions indicated in the report was the installation of a provisional roof with a metallic structure to protect the house against rainwater, which was one of the major causes of degradation. That suggestion was accepted by the municipality and implemented in the beginning of 2009 . The installation of the metallic roof proved to be an efficient protection measure. It could be observed, in the following winters, that the water stopped, the walls dried up as well as the vegetation inside the house. Therefore, the degradation process slowed down, and the municipality gained some extra time to prepare an intervention.

\subsection{First three-dimensional surveying campaign}

Meanwhile, in 2006, Lisbon School of Architecture applied a research project on 3D documentation for funding by the Portuguese research agency, Technology and Science Foundation (FCT). After approval, it started in the end of 2007.
In this research project, in which Valflores was included as a case study (http://archc3d.fa.ulisboa.pt/galery.html), it was possible to develop some exploratory actions for recording and documentation. The focus of this research project was to understand the impact of the new (at that time) surveying technology of 3D laser scanning and the new research paths in photogrammetry, namely automatic and semi-automatic methods of 3D reconstruction, in the study and analysis of the architectural heritage within conservation, restoration and rehabilitation. So, in 2008, it was commissioned a laser scanning survey of the house and aqueduct. First, for safety reasons, only the exterior was surveyed. It was used a ZF 5006 scanner to capture 46 point clouds with multiple resolutions. Simultaneously, the municipality carried out a topographic survey of the entire property which included all the control data to geolocate the laser scanning survey. Moreover, in strategic viewpoints, it was gathered images to colorize the laser scanning point clouds. These viewpoints, although they include those that were used in laser scanning (scan station locations), were in greater number. This initial laser scanning survey allowed to have a preliminary perspective, quantified, about the integrity of the structures of the property, namely the house and the main aqueduct. For example, it was possible to conclude that the composition of the main facade of the house was ruled by the $22 \mathrm{~cm}$ palm (Figure 4 ), an ancient measurement unit. Also, about proportions, it was verified that the golden ratio is present in the composition of the facade.

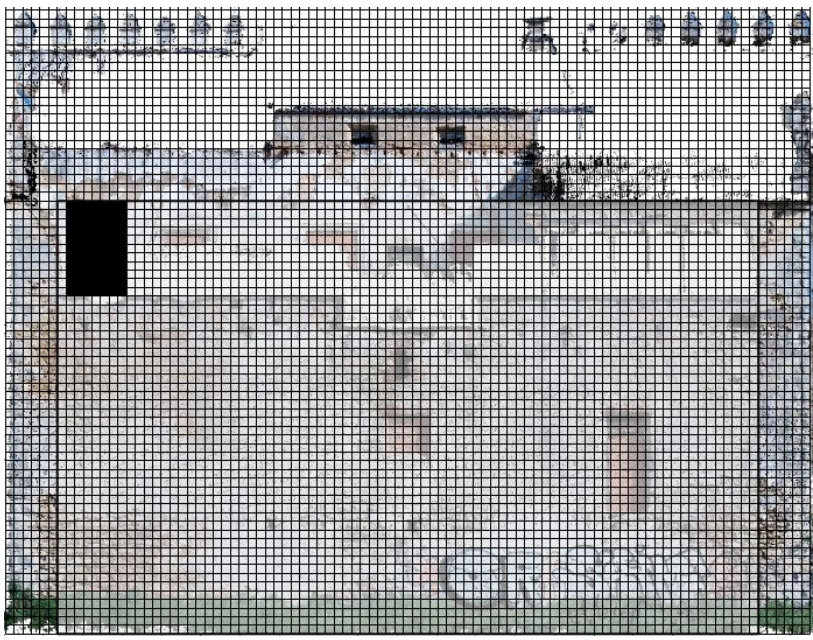

Figure 4. A $22 \mathrm{~cm} \times 22 \mathrm{~cm}$ grid overlaid to the front view of the main façade.

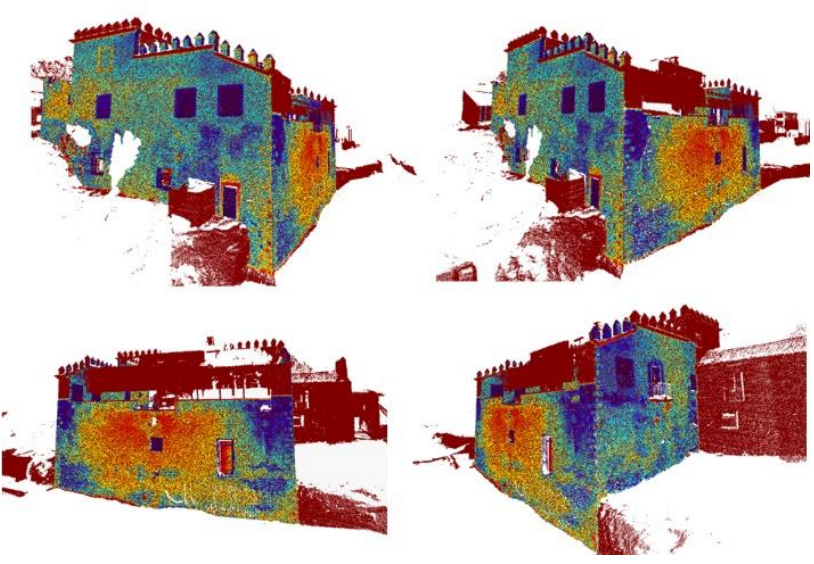

Figure 5. Deformation pattern of the facades. 
It was clear that some elements, probably later additions, did not comply with this metrics. In this way, it was possible to confirm that there was some degree of erudition in the architectural composition. Unfortunately, it was not found in the written sources who was the author of this design. Laser scanning data also permitted to quantify the deformation patterns of the facades and to visualise them in three dimensions (figure 5). It were noticed severe deformations of the walls which could be explained by the absence of roofs and corrosion of some structural metallic elements. At a more global scale, it was perceived the alignment between the aqueduct and the walls behind the house as it can be seen in figure 6. From this, and from the heights analysis, it was possible to conclude that the water transported by this structure was stored in a former tank next to these northern walls.

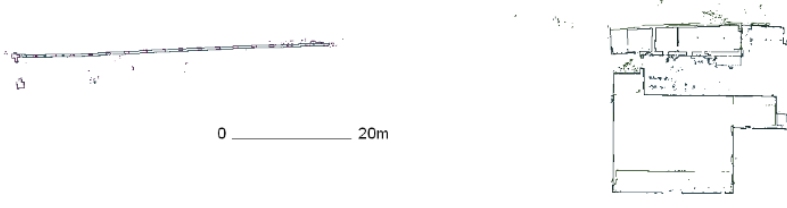

Figure 6. Alignment of the aqueduct and walls behind the house.

In fact, this preliminary surveying campaign allowed us to quantify some of the anomalies that were already evident at the naked eye.

In a second phase of this first campaign, in 2010, it was possible to access the interior of the house although it was not possible to access all rooms. Areas where ceilings had collapsed were not accessible yet. Other areas were walled either to avoid vandalism and for safety reasons due to anomalies in the supporting vaults. As it will be seen in the next section, it was only possible to access those areas in 2018 when the preparatory works of the interventions begun. Again, it was used a ZF 5006 Scanner to capture 47 point clouds for both floors. At the same time, and following the previous strategy, a thorough photographic survey was carried out. In figure 7 it is shown the adopted strategy to reach the higher parts of the building.



Figure 7. Using a hydraulic mast to reach the higher parts of the building.

The laser scanning survey of the interior was merged with the one from the exterior, generating a complete point cloud of the building. In figure 8 it is shown the distributive relations of the rooms in the main floor where it is clear, in the highlighted area, a typical layout of Italian villas of 16th century and is also evident the resemblance with the plan of plate 3 form Serlio's treatise, book 6. Form this survey it became clear that there were severe anomalies that were only compensated by the robustness and quality of the original construction. After this surveying action, all doors and windows were walled again for security reasons. All the elements produced in this survey campaign corresponded to exploratory research in the abovementioned research project. Although point cloud data acquisition was commissioned to an external company, all the processing was developed by the team in Lisbon School of Architecture. In the end of the research project, in 2011, finally it was possible to purchase a scanner. This date matched with the release of the Faro Focus 120S laser scanner that revolutionized laser scanning industry. This scanner was three times lighter, three times cheaper, and faster than the generality of the existing scanners at that time. So, in the following surveying campaigns this equipment was used.

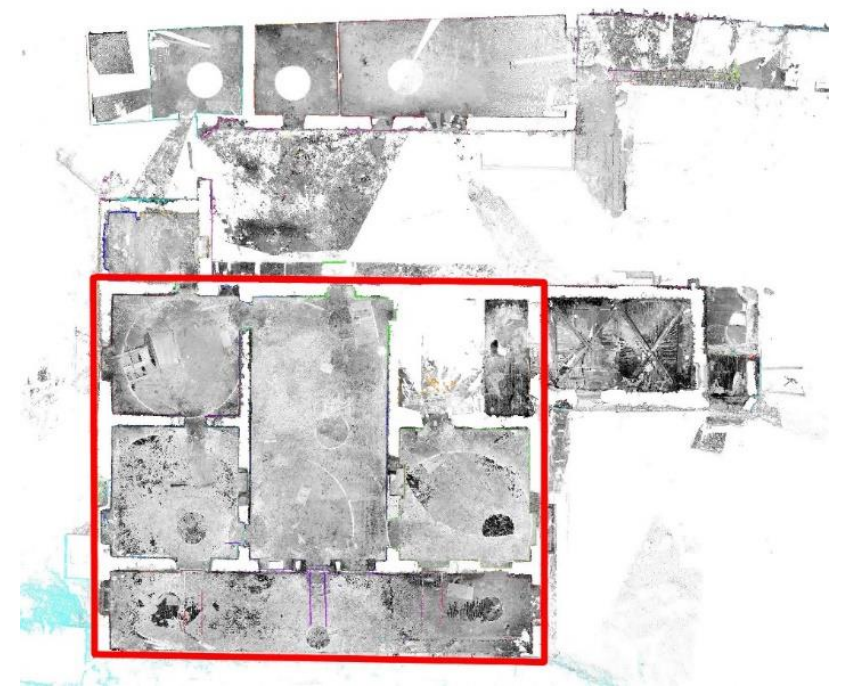

Figure 8. Planar view of the point cloud showing the first floor of the house.

During this period, in 2009, the local association, ADPAC, together with the municipality and Lisbon School of Architecture organized a colloquium and a debate entitled "Quinta de Vale de Flores Conhecer para salvaguardar" (Farm of Vale de Flores - To know to safeguard) where the values of this architectural heritage, the role of documentation for the safeguard process, the role of archaeology as a discipline in the conservation process, and the possible paradigms of architectural restoration in the 21 st century, were discussed. This was a relevant moment of reflection and public debate for the discussion about the future of Valflores. All the elements produced were delivered to the municipality. These served as basis for the preparation of all the necessary steps of the process that led to the elaboration of the restoration project in 2016. This project was a key element for the application for European Structural and Investment Funds submitted by the municipality.

\subsection{Second surveying campaign and the restoration project}

Between 2015 and 2016 the municipality commissioned a project for the structural consolidation of the house and aqueduct of Valflores. The project team included architects, conservators, engineers, and archaeologists. Initially the scope was only the structural consolidation, but the project team considered that it was fundamental to include the restoration of the roofs and rooms. Therefore, it was considered a global approach where all the values, from the building to the landscape, were observed. This way, the freedom for future interventions will be restricted in a positive way. These restrictions include the shape of the building and roofs, the way infrastructures need to be conceived (for example, functions related to the use of water cannot be installed 
in the house), the permanence of visual and aesthetical values, and the preservation of all the hydraulic structures. At the same time, after the interventions are concluded, the community will feel that something was done and that the investment was used in something that can be seen and used by the general public, at least to some extent. The risk of considering only the structural consolidation was that, in the end, the community would feel that nothing was done. This is because this type of intervention may not be easily perceived by the common person. It was also discussed and considered that the result of the intervention, which is not yet an architectural project for new uses, should permit that some activities could be developed. For example, art exhibitions, guided visits, artistic performances, among others. This way the local community can start to engage with this heritage and start felling it as theirs. To do this comprehensive intervention, as always, one of the problems was funding. To mitigate the risks, the project was divided in three phases as it was previously mentioned. Each of the phases was submitted for funding and, due to the quality of the application, all phases were considered eligible.

For the development of the restoration project it was decided to repeat the survey of the house. Two main reasons for that decision were considered. The first one was the fact that some changes occurred, for example the remaining columns of the loggia have fallen. The second one was the uncertainty about the actuality of data. It is a good practice that conservation actions are based in updated information, therefore a new survey was included as the first step of the restoration project. This was an important decision because it meant that everyone involved in the project could participate and follow the documentation process. In this way all the agents became more familiarized with the methods, the techniques, and the type of data produced. Therefore, part of the data processing and extraction was done with the staff of the architecture office and with the staff of the engineering office. In this phase it was fundamental to have an updated record of the existing conditions. Two methods were used. For an accurate geometrical survey, laser scanning was used. For an accurate description of the textures, digital photogrammetry was used.

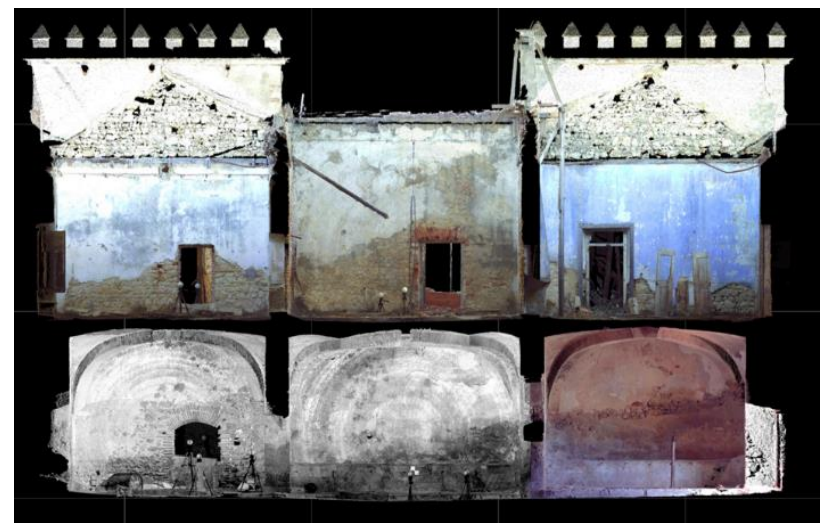

Figure 10. Ortho-image from laser scanning data from which drawings can be obtained.

The method used to produce the basic elements, such as plans, sections and elevations, was the cross reference between laser data (Figure. 10) and direct observations (Figure. 11). Laser data assured a global geometric soundness of recording. Direct observations resulted from a close contact with the real fabric, or with remains of the building stored in other locations. For example, the municipality stored some elements that were at risk, such as the loggia columns that fell and some tiles. Direct observation is fundamental in restoration and, although it can be enhanced by indirect methods like laser scanning or photogrammetry, it cannot be replaced by them.
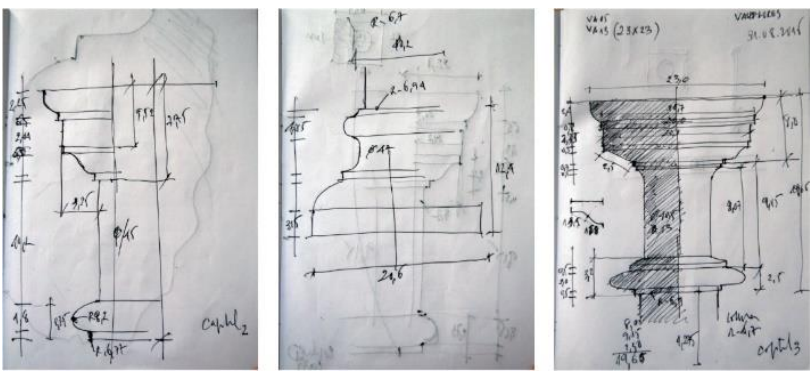

Figure 11. Direct observation drawings.

A correct geometry depiction was fundamental for the structural analysis, diagnosis, and intervention. In figure 12 it is shown an analysis of the deformation of the vaults of the ground floor. This analysis was done with laser scanning data. By analysing how the height map pattern changes, it is possible to understand the morphology and the type of deformations.

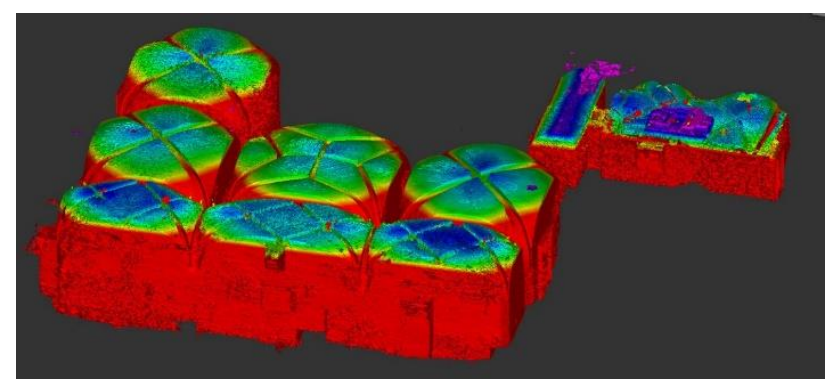

Figure 12. Analysis of the geometric deformation of the vaults in the lower floor.

The photogrammetric outputs are also important tools for the engineers and architects. They allow them to infer about the integrity of materials, to perceive singularities about the element's assemblage, to understand constructive patterns and methods and to provide the basis for anomalies recording (Figure. 13).

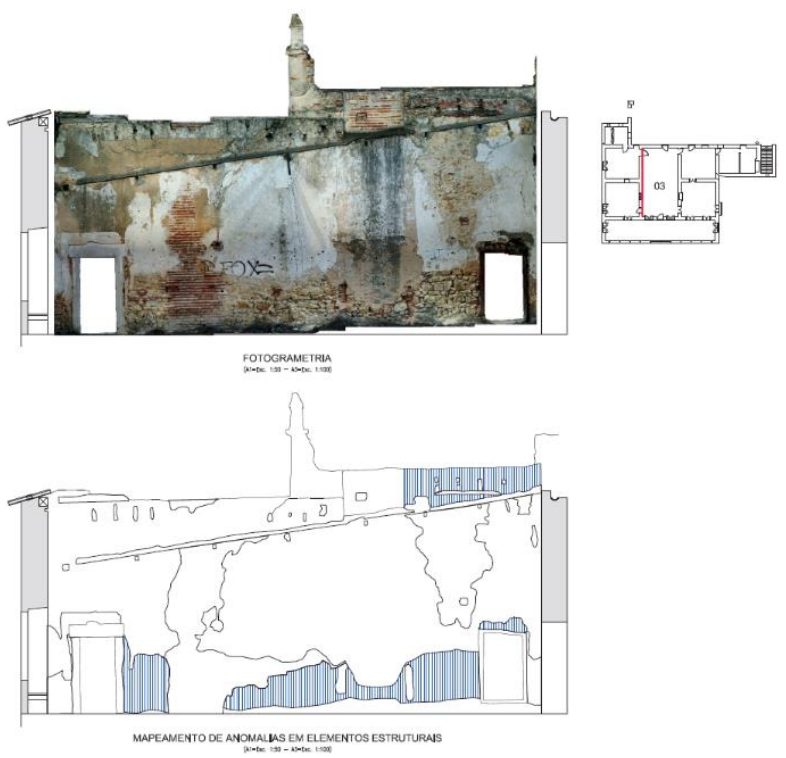

Figure 13. Anomalies recorded over a photogrammetric base.

With this data it was possible to document the existing condition and compare it with the desired outcome of the intervention, as it can be seen in figure 14 for the vaults of the loggia. The use of laser scanning proved to be fundamental for 
the observation and identification of anomalous structural behaviours. In Valflores, it allowed to understand the original constructive system, and to locate the main focuses of anomalies. Based on the deformed configuration it was possible to restore the original configuration and to decide about the adequate levels and methodologies for the restoration, considering the safeguard of the constructive and material authenticity of the elements to restore. In the vaults, whenever possible, the reconstructions were done using the existing materials; and using compatible materials, techniques, and processes when necessary.
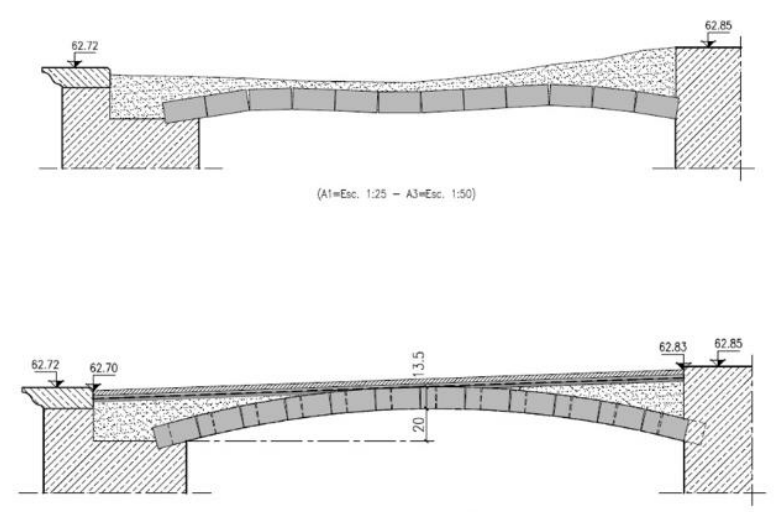

Figure 14. Cross section of the vault of the loggia. Top: existing, Bottom: to execute.

Moreover, all the prescribed interventions were mapped over drawings produced using these mixed sources and methods (Figure. 15).



Figure 15. Structural interventions schematized over the elevation drawings.

\subsection{Third surveying campaign during the construction works of phase 1}

The implementation of the conservation and restoration project was (and will continue to be) a dynamic process. This means that the project is sufficiently closed to allow a clear estimation of costs and timings. But, at the same time it is intended to be flexible enough to allow the incorporation of new findings that may result from the works. That is, phase 2 can be redefined if significant new elements are discovered in phase 1. And the same for phase 3 . There is a strong commitment between architecture, engineering, archaeology, conservation, history, to strongly contribute for the discussion as the construction works evolve and the analysis consolidate. This means a continuous methodological adjustment to the process. Of course, this also corresponds to some difficulties because public procurement rules are rigid and are not adapted to this approach.
The archaeological analysis started with the architectural project but strongly continued during the works of phase 1 so that it can benefit from those works. As the works started with the cleaning and removal of the debris of the collapsed elements, archaeologists had the opportunity to inspect and record those elements and had access to rooms there were not accessible before. In this process, all the relevant elements were inventoried and stored (nails, wood elements, stones, etc.).

Given the fact that, by definition, when we intervene in existing fabric there are unknown things a priori, which are only unravelled as works advance, there needs to be a commitment of all the partners to accept some degree of uncertainty. This means continuous adaptation and implies a continuous update of the records. An example of this can be seen in figure 16. The upper left corner (A) corresponds to survey done in 2016 for the preparation of the intervention project. When the works started, the room was cleaned and in 2018 it was possible to survey the interior of the room as well as the adjacent space in the right side (B). Later, in 2019, two other surveys were done, one after the removal of the roof (C) and another one after intervention in the walls (D).

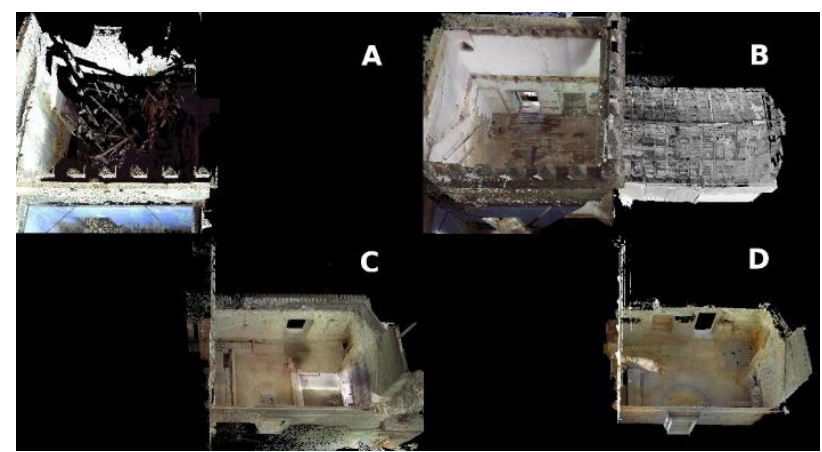

Figure 16. Continuous update of the laser scanning survey. A: For the project, B, C and D: During construction works.

From the practical point of view, for the archaeology analysis, the ortho images generated using laser scanning and photogrammetry were used as the support for field work (Figure. 17) and for the final records and reports.

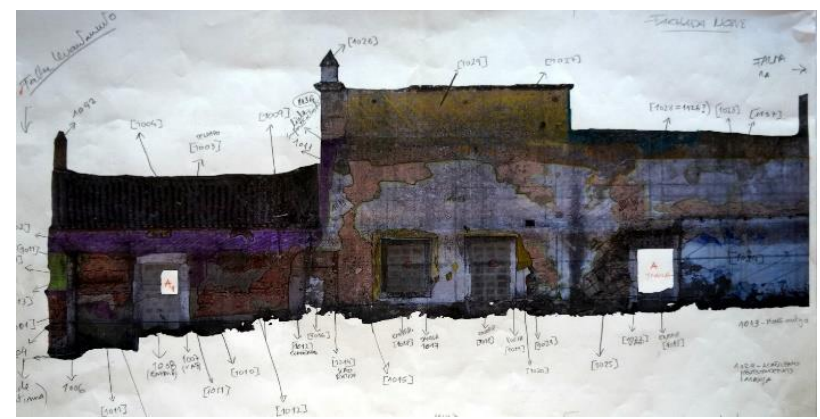

Figure 17. Archaeology field work record.

During the first phase of construction, in which the work focused on the house and the aqueduct, the team deepened the project in the landscape dimension. For this, it was also necessary to complement the surveys to document all the existing structures of the farm. For that reason, another laser scanning survey was done. This time it was intended to capture the topography, the support walls of the platforms, the morphology of the water stream, and the remains of the hydraulic structures (Figure. 18). 


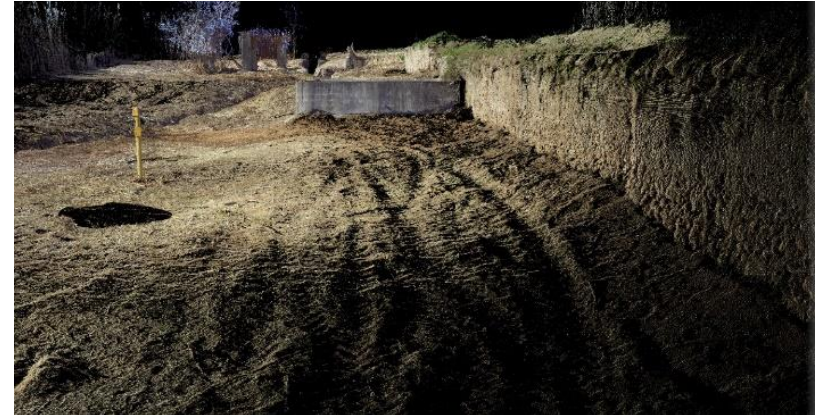

Figure 18. Exterior survey with laser scanning in 2018.

\subsection{Other uses for graphic data, in addition to the project} and construction works

During all this process (which is still ongoing) it worth's to mention a series of other initiatives and actions that have given a major contribution for the discussion about the future of Valflores and for which, graphical data produced with laser scanning and photogrammetry had an important role.

At Lisbon School of Architecture, in the academic years of 2016/17 and 2017/18, Valflores was used as a case study in the semi-annual course on Conservation, Restoration and Rehabilitation. The students were briefed by the municipality and by ADPAC and were challenged to develop proposals for what could be the future use for this Heritage. This was very important from many points of view. It was an excellent way to put the students in contact with a real case and gave them the opportunity to incorporate new types of data (point clouds, meshes, ortho-images) and methods (laser scanning, digital photogrammetry) in a workflow where the major decisions are of cultural nature. This way it contributed to the reinforcement of their technical and cultural background, preparing them for the future challenges of the architect's profession. The results of this work were presented to the municipality and presented in a public exhibition (Figure. 19).

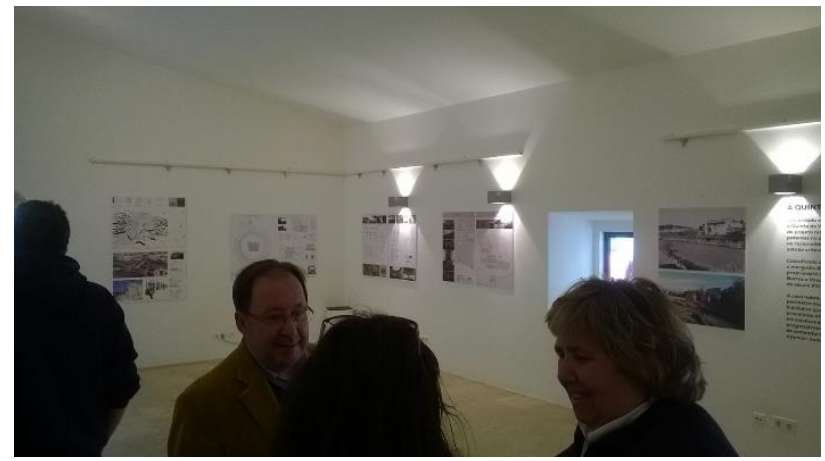

Figure 19. Public exhibition of the student's work.

A major contribution of this process is the collection of a multitude of hypothesis for the use and occupation of Valflores. This can be used by the municipality as inspiration for the future. It is evident that the possibility to have some dozens of enthusiastic young students developing ideas is a major opportunity to test a broad range of possibilities.

Another interesting use for the data produced was its dissemination, and systematic storage, through the social networks. The local association ADAPC had a major role in this initiative. This permitted that the local community, which at the present date does not have physical access to this heritage, could follow the development of the process. Periodically, texts, images, and videos were posted. Among other things, images from the surveying process and videos of the $3 \mathrm{D}$ models were posted. It contributed to familiarize people with these methods and at the same time to engage them with the entire process. Even if they do not become experts, at least words like heritage value, safeguard, laser scanning, photogrammetry, documentation, archaeology, and many others become more familiar. And this is also education.

In 2019, ADPAC promoted an initiative entitled "The days of renaissance" aimed to promote the interconnection between local stakeholders and local heritage, with a specific focus on Valflores. It was an opportunity to discuss the future and to celebrate the starting and conclusion of the works of phase 1 . It were organized several talks with different experts, walks to visit the construction site, exhibitions to show the works done, thematic artistic performances with music, literature, and theatre. In this context there was an unexpected use for laser scanning data. Images where extracted from the point clouds, printed in canvas and included in one of the exhibitions. The aesthetic of the images made visitors compare them to paintings (Figure. 20) strengthening the bonds between art and science.

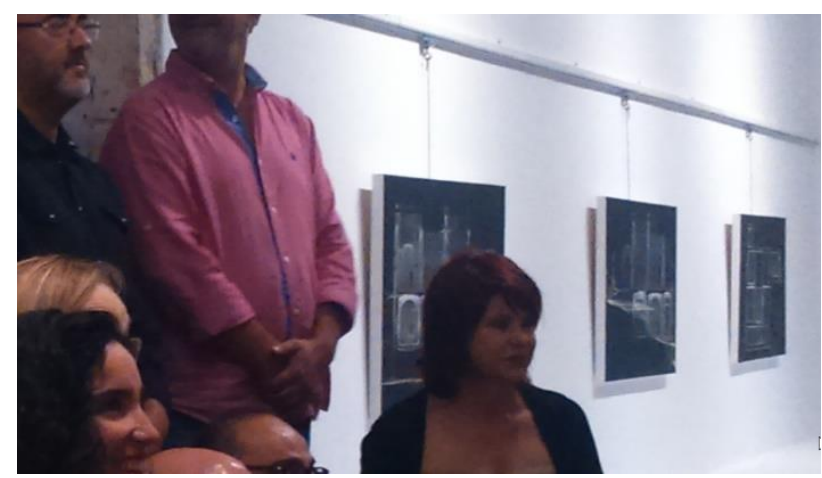

Figure 20. Public exhibition where point clouds were transformed in "paintings".

\section{DISCUSSION AND CONCLUSIONS}

The intervention in heritage can be a long process where multiple agents and stakeholders intervene. It should be mostly a process of knowledge acquisition that, in the end, will legitimate the physical actions upon a theory of values. The survey methods of laser scanning and photogrammetry, complemented with traditional methods, can provide reliable data to feed the discussion about the recognition of the heritage values. The materials produced with such methods were used throughout the several steps of the process; before, during and after the intervention works. They are important for the architect because they are powerful tools to prepare all the basic graphic information to be used as basis for the architectural designs. Their systematic use during the process permitted a continuous update of information and to keep faithful and accurate records of the site. Moreover, data could be revisited as needed and further elements could be extracted. For the conservators, the continuous description of the surfaces is a very important tool for the anomaly's assessment and recording. For the structural engineer, the method of laser scanning is an essential tool when there is the need to restore masonry structures. One of the great advantages, beyond the record and storage of all the geometrical configuration of the construction, is the record and visualization of all the deformations of pavements, slabs, and walls. In the case of vaulted structures, it is very relevant the observation of their altimetric configuration, from which anomalous behaviours can 
be recognized. In the structural rehabilitation of Valflores built fabric it was possible to understand the original construction system, learn from it, and integrate that knowledge in the project. For archaeology, the possibility to have continuously updated records, facilitated the stratigraphical analysis. Before an intervention, the actual state was recorded and analysed. Then, during the intervention, when needed, new surveys were conducted from which new analysis could be done, in a continuous iterative process, enriching the intricate matrix of interconnections of all the elements of the site.

The use of laser scanning also contributed for the team to work together using the same basis and reference system. This way, all the elements produced were perfectly integrated and coherent.

Moreover, laser scanning and photogrammetry deliverables were used beyond the "professional" side of the process. They were used in academic context, where architecture students from Lisbon School of Architecture participated in the development of proposals for Valflores. From the educational point of view this was an important achievement. We believe that the students should be familiarized with tools and methods that most probably they will need to use in the future.

Social networks were also a powerful dissemination media. Images, texts, and videos can be easily shared and accessed by everyone. This helped the local community to follow the intervention process and to engage with this heritage which is, in first place, their own heritage. The local association, ADPAC, had a very important role contributing to put together all the stakeholders. A testimony of this fact was the "The days of Renaissance" initiative. There, it was the opportunity to transform technology in art when the point clouds were presented as "paintings". The reception of this technology transformed in an art form was very interesting. The views were not literal nor explicit. There were transparencies, multiple planes, in orthogonal projections that do not correspond to the common perspective view. For the first time, some people understood the underlying structure of the building, what was in front and in the back, related different parts that were unknown for them. There was both the aesthetical appraisal and the sense of learning something new. This is a dimension that worth's to explore further.

Overall, the methods of laser scanning and photogrammetry were inseparable from all the process, from its early stages to the present day. They were perfectly integrated in the intervention process being used whenever needed. Additionally, as time passed, the team developed skills to manage and process this type of data. We can say that we are no longer in a phase where the methods are strange and very specialized. On the contrary, at the present days, these methods are, more and more, part of the daily routine of all the agents that deal with heritage.

\section{REFERENCES}

Cramer, J. and Breitling, S, 2007. Architecture in existing fabric - Planning Design Building. Berlim, Birkhauser. ISBN 978-37643-7751-9

Fernández, J., Mateus, L. 2019b. Solution supporting the communication of the built heritage: Semi-automatic production path to transfer semantic LIDAR data to minecraft environment. Digital Applications in Archaeology and Cultural Heritage, Vol. 14, e00112, p. 1-12, https://doi.org/10.1016/j.daach.2019.e00112
Hoon, Y.J., Hong, S., 2019. Three-dimensional digital documentation of cultural heritage site based on the convergence of terrestrial laser scanning and unmanned aerial vehicle photogrammetry. ISPRS International Journal of GeoInformation, 8(2), https://doi.org/10.3390/ijgi8020053

Mateus, L., Fernández, J., Ferreira, V., Oliveira, C., Aguiar, J., Gago, A. S., Pacheco, P., and Pernão, J. 2019a. Graphical data flow based in TLS and photogrammetry for consolidation studies of historical sites. The case study of Juromenha fortress in Portugal. In: The International Archives of the Photogrammetry Remote Sensing and Spatial Information Sciences, Vol. XLII2/W15, p. 767-773, https://doi.org/10.5194/isprs-archives-XLII2-W15-767-2019

Mateus, L., Fernández, J., Ferreira, V., Oliveira, C., Aguiar, J., Gago, A.S., Pacheco, P., Pernão, J. 2019b. Terrestrial laser scanning and digital photogrammetry for heritage conservation: Case study of the historical walls of Lagos, Portugal. In: The International Archives of the Photogrammetry, Remote Sensing and Spatial Information Sciences, Vol. XLII-2/W11, p.843-847, https://doi:10.5194/isprs-Archives-XLII-2-W11-843-2019

Noé, P., Bandeira, F. and Rodrigues, H., 2001. Palácio e Quinta de Valflores. In: SIPA (Sistema de Informação do Património Arquitectónico), last access in january 2020, http://www.monumentos.gov.pt/Site/APP_PagesUser/SIPA.asp $\mathrm{x}$ ?id $=6316$

Pires, A. G., 2013. A Quinta de Recreio em Portugal Vilegiatura, Lugar e Arquitectura. Lisboa, Caleidoscópio Edição e Artes Gráficas, SA. ISBN 978-989-658-245-6

Remondino F. and Rizzi A., 2010.Reality-based 3D documentation of natural and cultural heritage sites - techniques, problems, and examples. Applied Geomatics, Vol.2(3), p. 85100, https://doi.org/10.1007/s12518-010-0025-x 